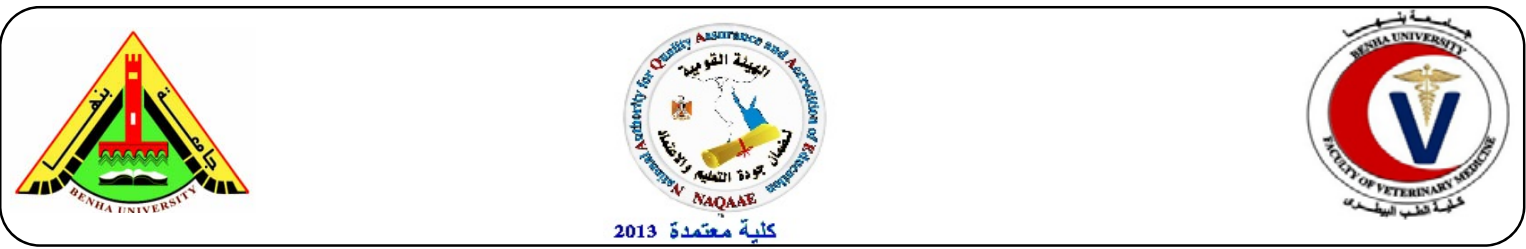

\title{
Morphological studies and immunohistochemical detection of leptin and s-100 protein on the uropygial gland of baladi duck
}

\author{
Rasha R. Beheiry \\ Department of Histology and Cytology. Faculty of Veterinary Medicine, Zagazig University, zagazig, \\ Egypt. Email: rasharagab2006@yahoo.com
}

\begin{abstract}
A B S T R A C T
Immunoperoxidase methods for the demonstration of leptin and S-100 protein were applied in routinefixed paraffin sections on the uropygial gland of baladi duck. Intact uropygial glands from twenty adult healthy duck were used after slaughter. The glands were removed then the tissue specimens were fixed in $10 \%$ buffered neutral formalin. This study showed that the uropygial gland formed from two lobes, which were encapsulated by a connective tissue capsule. Each lobe composed of peripheral tubules and central tubules that separated by connective tissue septa. The epithelial cells of the secretory tubules were consisted of four layers, the germinative, intermediate, secretory and degenerative cells. Immunohistochemical examination revealed that the leptin immunoreactivity was distributed in both the peripheral and the central tubules. The leptin immunostaining was strong in the basement membrane, the cytoplasm of germinative cells, secretory cells and degenerative cells. In addition, strong reaction to leptin antibody was seen in the lumen or central cavity of central tubules. Additionally, S100 immunoreactivity was detected strong in the capsule and with moderate reaction on the cytoplasm of peripheral and central tubules. This study emphasized that the strong positive reaction to leptin immunostaining in the secretion of central tubules reflect the nature of secretion of the preen wax. In addition, the expression of S100 protein immunostaining may indicate specific functions.
\end{abstract}

Key words: Duck, Leptin, S100 protein, uropygial gland.

(http://www.bvmj.bu.edu.eg)

(BVMJ-29(1): 1-8, 2015)

\section{INTRODUCTION}

$\mathrm{T}$ The avian skin with the preen gland and the ear glands as specialized parts act as a sebaceous secretory organ (Menon et al., 1981). The uropygial gland (preen gland) (oil gland) is a bilobed structure on the base of the tail (Peter and Stettenheim, 2000). Inside a connective tissue capsule, each lobe is composed of numerous holocrine secretory alveoli that open into a central cavity (Menon et al., 1981; Jacob and Ziswiler, 1982). Uropygial gland is bigger in water-birds than landbirds, and is present in most bird species while absent or vestigial in some other species (Bell and Freeman 1971 and Johnston, 1988). Each lobe, which is separated by an interlobular septum, has a central cavity, which opens to the nipple like papilla at the top of the skin via the central duct (Kolattukudy, 1981 and Aughey and Frye, 2001). The tubular epithelial cells of uropygial gland are classified into four well defined layers: a) agerminative layer, b) an intermediate layer, c) a secretory layer and d) a degenerative layer. Cell fragments, corneous plates and secretion form the sebum (Jacob, and Ziswiler. 1982) and (Liman and Alan, 2013) in the chicken uropygial gland. Leptin is a polypeptide hormone. This cytokine-like hormone is mainly produced in the adipose tissue and released into the blood stream when the fat storage increases (Zhang et al., 1994). In the 